\title{
Pulmonary Intralobar Sequestration Accompanied by Aneurysm of an Anomalous Arterial Supply
}

\author{
Akio Koyama, Katsuhisa Sasou, Haruhisa Nakao, Asamitsu Hirano, Hitoshi Hachiya, \\ Masao Iwasaki, Kunio Nanjo, Masao KozuKa, Masaaki Sano* and Norio Sumita*
}

A 47-year-old woman presented with hemoptysis and her chest $\mathrm{X}$-ray films showed an opacity suggesting a mass in the left lower lung field. Based on radiographic investigations, the mass was diagnosed as an aneurysm develop in an anomalous vessel and was considered to be a Pryce type I pulmonary intralobar sequestration. Resection of the left lower lobes was performed and the aneurysm was found to be filled with thrombus. It is rare for an aneurysm to form in an aberrant vessel. This complication may have been the result of regional sclerosis affecting the anomalous artery as well as systemic atherosclerosis.

(Internal Medicine 31: 946-950, 1992)

Key words: Pryce type I, hemoptysis, thrombus

\section{Introduction}

Pulmonary sequestration is the term used when an aberrant artery of the systemic circulation system directly supplies an area of the lung parenchyma; this is believed to be a rare condition. This malformation was first reported by Huber (1) in 1777, and was later classified into 3 types by Pryce (2) in 1946, based on the pattern of pathology. Since the name pulmonary sequestration was given to this vascular anomaly, it has attracted clinical attention and an increasing number of case reports have been published in the literature.

Here, we report our recent experience with a case of pulmonary sequestration accompanied by a thrombotic aneurysm of anomalous vessels.

\section{Case Report}

The patient, a 47-year-old woman, had the chief complaint of hemoptysis. Both parents died of cerebral hemorrhage. For the past several years, she had suffered from hypertension but it was left untreated. She developed myocardial infarction in June 1988, and subsequently visited a general practitioner for treatment. Cerebral infarction occurred in January 1989. She had light hemoptysis in January and July of 1989, and then she was transferred to this hospital. Before the onset of myocardial infarction she had been obese as well as a heavy smoker and drinker, with a daily intake of about 60 cigarettes and about $1,000 \mathrm{ml}$ of rise wine (sake) for over 20 years. On admission, she appeared well-nourished, with an average physique. Left hemiplegia and dysarthria were present. There were no abnormal findings on physical examination of the chest and abdomen. Hematological tests on admission, including hemogram, biochemical tests, and serology tests showed no abnormalities.

On chest X-ray (Fig. 1), the frontal radiograph demonstrated an irregularly shaped mass $(4.6 \times 3.1 \mathrm{~cm})$ with a relatively clear margin that overlapped the cardiac silhouette in the left lower lobe. Frontal tomograms confirmed the presence of the mass in the left lower lung $\left(\mathrm{S}^{10}\right)$, and showed internal nonhomogenous attenuation of the lesion. An electrocardiogram demonstrated left vertricular hypertrophy with moderate ST-T changes. No relevant ECG record showing myocardial infarction was available. Chest CT scanning (Fig. 2), a computed tomographic (CT) scan of the chest disclosed an irregular mass abutting the descending aorta and heart. A nonhomogenous internal structure and partial calcification of this mass were suggested by internal mottling due to areas of decreased attenuation. Some parts of the mass were well enhanced by the injection of contrast material. Bronchography (Fig. 3), partial displacement and narrowing of the left basal bronchial tree due to pressure by the mass, but no filling defect or cyst formation was

From the Department of Internal Medicine and *the Department of Surgery, Nagoya Municipal Josai Hospital, Nagoya

Received for publication July 15, 1991; Accepted for publication April 17, 1992

Reprint requests should be addressed to Dr Akio Koyama, the Department of Internal Medicine, Nagoya Municipal Josai Hospital, 4-1 Kitabatake-cho, Nakamura-ku, Nagoya 453, Japan 


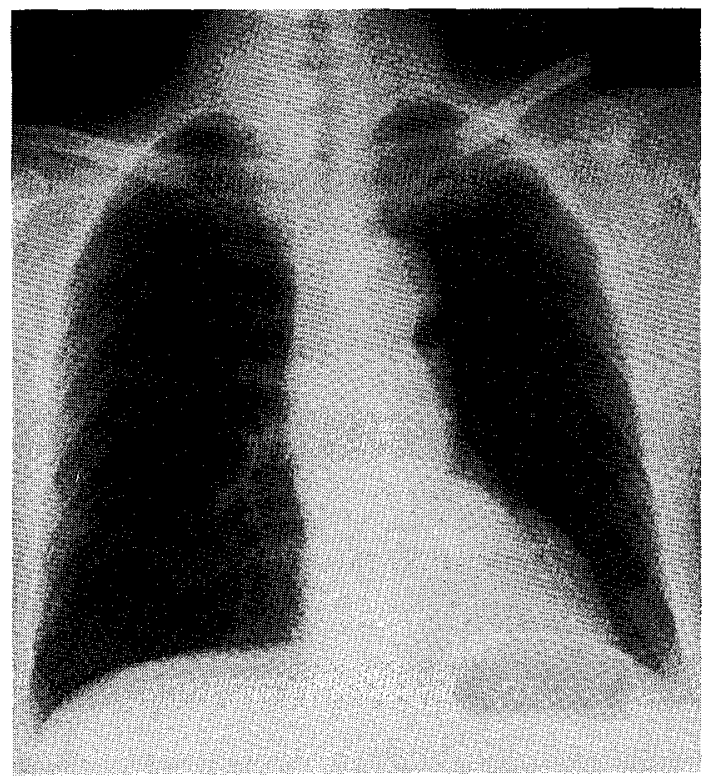

Fig. 1. Chest $\mathrm{X}$-ray film showing an irregularly shaped mass that overlapped the cardiac silhouette on the left.

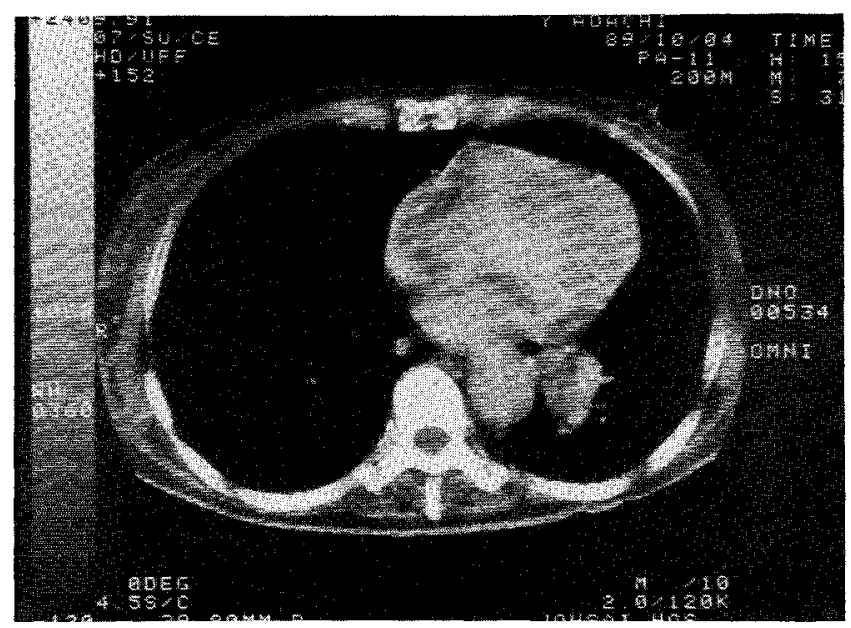

Fig. 2. Chest CT scan showing an irregularly shaped mass abutting the descending aorta and heart.

found. Pulmonary angiography using DSA (Fig. 4), the pulmonary tree revealed a poor distribution of vessels in the left basal lung segment. Angiography of the thoracic aorta (Fig. 5), in the arterial phase showed an abnormal extension of the aorta into the left lower lung field at the 8th thoracic vertebral level, and further peripheral branching was also revealed. The venous return entered the lower pulmonary vein in the venous phase of the thoracic aortogram.

Based on these findings this case was diagnosed as intralobar sequestration of the left lung base, and the mass shown on the X-ray films was considered to be present in the anomalous artery supplying the sequestrated lung. Therefore, thoracotomy was performed. During thoracotomy, an incision was made over the 6 th rib, and

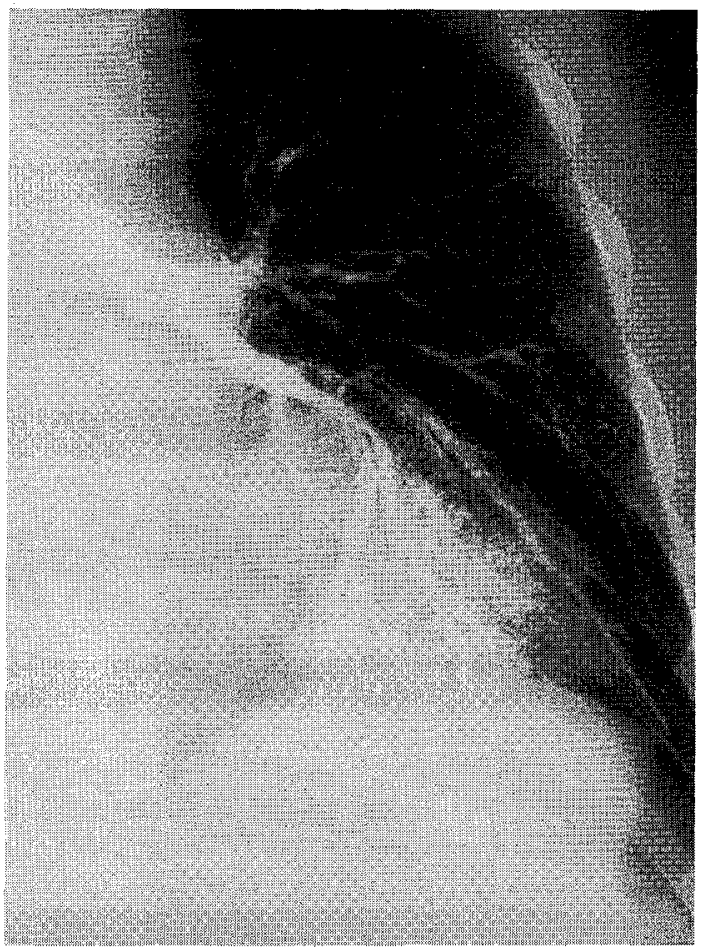

Fig. 3. Left bronchography showing partial displacement and narrowing due to pressure by the mass, but there were no filling defects or cyst formation.

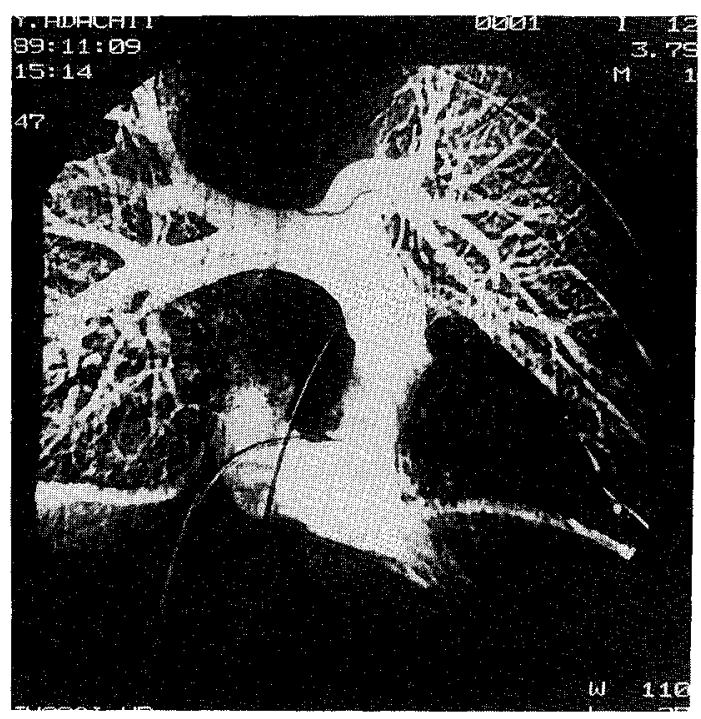

Fig. 4. Pulmonary angiography (using DSA) showing a poor distribution of vessels in the left lower lung field.

the abnormal arterial supply leading into the left lower lobe and arising from the descending aorta was found at the T8 level. The vessel was $1.7 \mathrm{~cm}$ in diameter at its origin, and showed cystic dilatation where it entered the lung, forming an aneurysm $3.5 \mathrm{~cm}$ in diameter at the widest point. This anomalous vessel was excised at the root; the aortic site was patched and then the lower lobe of the left lung was resected. 


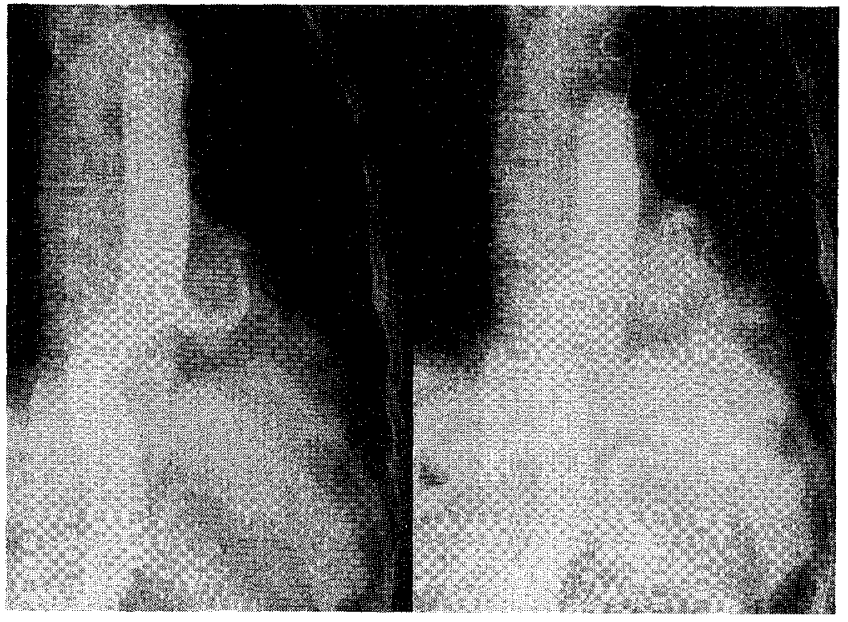

Fig. 5. Thoracic aortogram showing an abnormal extension of the aorta into the left lower lung field, and the venous return which entered to the lower pulmonary vein.

Arteriography of the resected lobe including the anomalous vessel and the branch pulmonary artery was performed (Fig. 6). Arteriography of the anomalous artery (the lower vessel) revealed the presence of an aneurysm with irregular filling defects and then visualized the basal segment of the lung. Only $\mathrm{A}^{6}$ was enhanced by the injection of contrast medium into the branch of the pulmonary artery supplying this lobe (the upper vessel).

On observation of the cut surface of the resected lobe after fixation, no cystic or emphysematous change

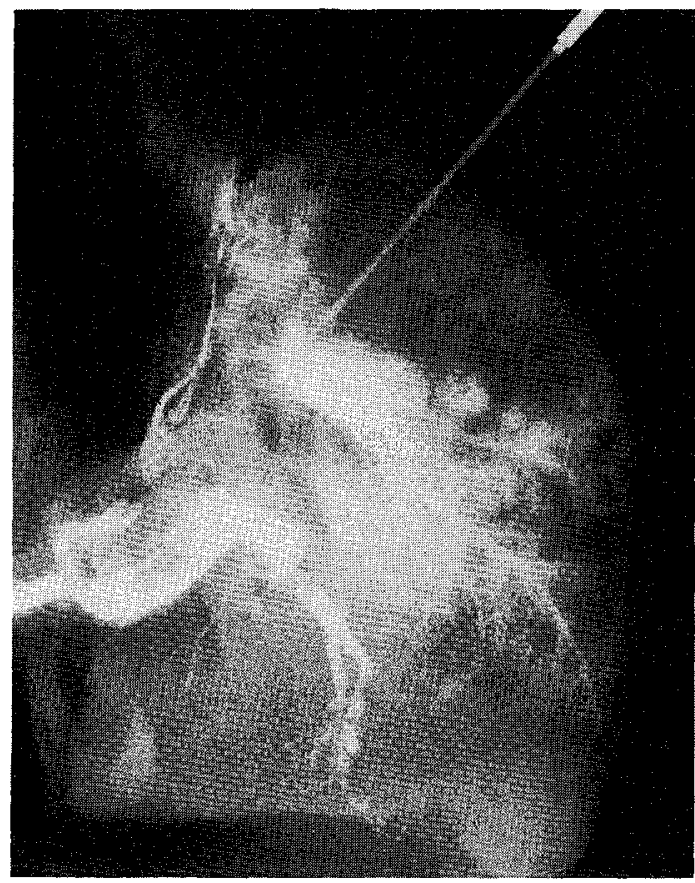

Fig. 6. Arteriography of the resected lobe. Anomalous arteriography (the lower vessel) showing the presence of an aneurysm and the basal segment. Pulmonary arteriography (the upper vessel) showing only $\mathrm{A}^{6}$ lobe to be enhanced.

was seen in the basal lung segment. The inside of the aneurysm was filled with thrombus. Examination of the origin of the anomalous artery revealed distinct intimal

Table 1. The Case Reports of Pryce Type I Intralobar Pulmonary Sequestration in Japan

\begin{tabular}{|c|c|c|c|c|c|c|c|c|c|c|}
\hline \multirow{2}{*}{$\begin{array}{l}\text { Case } \\
\text { No. }\end{array}$} & \multirow{2}{*}{$\begin{array}{l}\text { Age } \\
\text { and } \\
\text { sex }\end{array}$} & \multicolumn{7}{|c|}{ Abnormal artery } & \multirow{2}{*}{$\begin{array}{l}\text { Published } \\
\text { year }\end{array}$} & \multirow{2}{*}{$\begin{array}{c}\text { Reference } \\
\text { No. }\end{array}$} \\
\hline & & & Location & Origin & No. & $\operatorname{Size}(\mathrm{mm})$ & Venous return & Aneurysm & & \\
\hline 1 & $27 \mathrm{M}$ & $\mathrm{L}$ & BS & Thor. aorta & & & & & 1956 & 5 \\
\hline 2 & $34 \mathrm{M}$ & $\mathrm{L}$ & BS & Thor. aorta & 1 & 8 & LPV & $(-)$ & 1956 & 6 \\
\hline 3 & $12 \mathrm{M}$ & $\mathrm{R}$ & $\mathrm{S} 10$ & Thor. aorta & 1 & 8 & LPV & $(-)$ & 1971 & 7 \\
\hline 4 & $28 \mathrm{~F}$ & $\mathrm{R}$ & $\mathrm{LL}$ & Thor. aorta & 1 & & LPV & $(-)$ & 1973 & 3 \\
\hline 5 & $24 \mathrm{M}$ & $\mathrm{L}$ & LL & Thor. aorta & 1 & & LPV & $(-)$ & 1973 & 3 \\
\hline 6 & $18 \mathrm{~F}$ & $\mathrm{~L}$ & BS & Thor. aorta & 1 & 10 & LPV & $(+)^{*}$ & 1975 & 8 \\
\hline 7 & $6 \mathrm{~F}$ & $\mathrm{R}$ & $\$ 9+10$ & Abd. aorta & 1 & 10 & UPV & $(-)$ & 1976 & 9 \\
\hline 8 & $37 \mathrm{M}$ & $\mathrm{R}$ & $s 9+10$ & Thor. aorta & 1 & 10 & LPV & $(-)$ & 1978 & 10 \\
\hline 9 & $5 \mathrm{M}$ & $\mathrm{L}$ & $\mathrm{S} 10$ & Thor. aorta & 1 & & LPV & $(-)$ & 1978 & 11 \\
\hline 10 & $5 \mathrm{M}$ & $\mathrm{L}$ & BS & Thor. aorta & 1 & 11 & LPV & $(-)$ & 1979 & 12 \\
\hline 11 & $9 \mathrm{~F}$ & $\mathrm{R}$ & $\mathrm{LL}$ & Celiac a. & 5 & $1-5$ & LPV & $(-)$ & 1982 & 13 \\
\hline 12 & $26 \mathrm{M}$ & $\mathrm{L}$ & BS & Thor. aorta & 1 & & LPV & $(-)^{*}$ & 1983 & 14 \\
\hline 13 & $1 \mathrm{~F}$ & $\bar{L}$ & BS & Thor, aorta & 1 & 8 & LPV & $(-)$ & 1985 & 15 \\
\hline 14 & $38 \mathrm{~F}$ & $\mathrm{~L}$ & $\mathbf{L L}$ & Abd. aorta & 1 & 7 & LPV & $(-)$ & 1987 & 16 \\
\hline 15 & $53 \mathrm{M}$ & $\mathrm{L}$ & $\mathrm{S} 9+10$ & Thor. aorta & 1 & 15 & LPV & $(-)$ & 1988 & 17 \\
\hline 16 & $16 \mathrm{M}$ & $\mathrm{L}$ & $\mathrm{BS}$ & Thor. aorta & 1 & 6 & LPV & $(-)^{*}$ & 1988 & 18 \\
\hline 17 & $50 \mathrm{M}$ & $\mathrm{L}$ & BS & Thor. aorta & 1 & 16 & LPV & $(-)$ & 1988 & 19 \\
\hline 18 & $61 \mathrm{M}$ & $\mathrm{L}$ & BS & Thor. aorta & 1 & 7 & LPV & $(-)^{*}$ & 1989 & 20 \\
\hline 19 & $13 \mathrm{M}$ & $\mathrm{L}$ & $\mathrm{S} 10$ & Thor. aorta & 1 & 8 & LPV & $(-)^{*}$ & 1990 & 21 \\
\hline 20 & $20 \mathrm{~F}$ & $\mathrm{~L}$ & $S 8+9+10$ & Thor. aorta & 1 & 8 & LPV & $(-)$ & 1990 & 22 \\
\hline 21 & $47 \mathrm{~F}$ & $\mathrm{~L}$ & BS & Thor. aorta & 1 & 17 & LPV & $(+)^{*}$ & Present case & \\
\hline
\end{tabular}

BS: basal segment, LL: lower lobe, LPV: lower pulmonary vein, UPV: upper pulmonary vein.

* Dilatation. 
thickening due to severe atheromatous degeneration and destruction of the internal elastic lamina.

This patient did not have any pulmonary arterial branches in the left basal pulmonary segment, rather there was an aberrant artery which arose directly from the descending thoracic aorta. The bronchial system was normal. Therefore, Pryce type I intralobar sequestration of the left lung base was diagnosed in this patient. The thrombotic aneurysm that developed in the aberrant artery appeared as a mass on the chest X-ray films.

\section{Discussion}

In 1974, Pryce (2) classified this disease into 3 pathological types. The present case was a type I pulmonary sequestration, due to the abnormal arterial supply to normal lung tissue.

Pryce type I pulmonary sequestration is rarely seen, in contrast to types II or III $(3,4)$. As far as could be determined, only 21 cases have been reported $(3,5-22)$ in Japan, including the present case (Table 1). Six patients had anomalous arteries which were dilated after branching off from the systemic arterial supply $(8,14,18,20,21)$, and only 2 of these (8) had an aneurysmal dilatation of the anomalous vessel. Furthermore, the present case was the only case where a cystic dilatation of the anomalous artery was filled with thrombus among the previous domestic case reports.

The world literature includes 400 case reports of pulmonary intralobar sequestration as reviewed by Savic et al (23), but none of these were similar to the present case. Only the 2 cases reported by Schuman et al (24) and Mclaughlin et al (25), resemble the present case, although they were not Pryce type I lesions.

It has been thought that an anomalous artery exposed to the high blood pressure of the aorta is liable to undergo local changes, leading to regional sclerosis, and sclerosis localized in an abnormal arterial supply has been reported in many cases. However, one report (8) suggested that no lesions of the lung tissue occur as a result of the buffering effect of aneurysmal dilatation of the anomalous artery reducing systemic hypertension. There are only a limited number of cases of structural abnormalities in the adjacent lung tissue, even among the patients without dilated feeding vessels or those with an aberrant vessel dilated in a non-aneurysmal form. This suggests that the contribution of an aneurysm in the protection against potential lung injury can be ruled out.

The present patient was not elderly (47 years old), and no abnormalities of lipid metabolism or obesity were found on admission. However, she used to be obese, was a heavy drinker and smoker, and suffered from hypertension, myocardial infarction, and cerebral infarction. Also, the anomalous vessel showed severe intimal thickening due to atheromatous degeneration, destruction of the internal elastic lamina, and loss of the intima and media of the aneurysmal wall with thrombus filling the lumen. These findings indicated that the aneurysm in the present patient had been formed by regional sclerosis in the anomalous feeding artery plus generalized arteriosclerotic changes.

\section{References}

1) Huber JJ. Observations aliquod de arteria sinngulari pulmoni concessa. Acta Helvet 8: 85, 1777. Quoted from Pryce DM(2).

2) Pryce DM. Lower accesary pulmonary artery with intralobar sequestration of lung: A report of seven cases. J Pathol 58: 457,1946

3) Shindo K, Iwai K, Yoneda R, et al. Treatment and pathology in 12 patients with pulmonary intralobar sequestration. Jpn J Chest Dis 32: 9, 1973 (in Japanese).

4) Campbell DC, Murney JA, Dominy DE. Systemic arterial blood supply to a normal lung. JAMA 182: 497, 1962.

5) Kondo T. A patient with pulmonary cyst. J Jpn Soc Intern Med 4: 923, 1956 (in Japanese).

6) Ito A, Kobayashi H. Congenital cystic disease of the lung associated with anomalous artery (a case report). Jpn J Thorac Surg 9: 1311, 1956 (in Japanese)

7) Harutani S, Washio M, Irisawa N, et al. Five cases of pulmonary sequestration with abnormal arterial blood supply. Surg Diagn Treat 13: 1278, 1971 (in Japanese).

8) Yamazaki S, Kawada K, Soma Y, Fukuda $T$, Inoue $T$, Mikata A. An aberrant systemic artery to the left lung with bronchial stenosis, patent ductus arteriosus and mitral insufficiency. J Jpn Assoc Thorac Surg 23: 1022, 1975 (in Japanese).

9) Masuda K, Iijima Y, Hirashima S, et al. Report of a case with the Scimiter-like syndrome. Jpn J Thorac Surg 29: 395, 1976 (in Japanese).

10) Iwamoto $T$, Watanabe $T$, Murashige A, et al A case of intralobar pulmonary sequestration associated with an accessary diaphragm and anomaly of inferior vena cava. $J$ Kyoto Pref Univ Med 87: 293, 1978 (in Japanese).

11) Hirose $\mathrm{O}$, Nishi $\mathrm{K}$, Makino $\mathrm{S}$, et al. Two patients with pulmonary intralobar sequestration causing a continuous murmur. Acta Pediatr Jpn 82: 873, 1978 (in Japanesc)

12) Ishihara $Y$, Fukuda R, Awaya $Y$, et al. Anomalous systemic arterial supply to the basal segments of the lung presenting with a murmur. Eur J Pediatr 131: 125, 1979.

13) Irisawa A, Yoshimura $\mathrm{H}$, Sonoda $\mathrm{K}$, et al. A case of Pryce type I pulmonary sequestration. Jpn J Chest Dis 41: 444, 1982 (in Japanese).

14) Miyake M, Tanaka N, Tagashira $Y$, et al. A lobe of the lung with systemic blood supply. Jpn J Chest Dis 42: 775, 1983 (in Japanese).

15) Ogawa $J$, Inoue $K$, Koide $S$, et al. A case of anomalous systemic arterial supply to the basal lung. Jpn J Thorac Surg 38: 316, 1985 (in Japanese).

16) Kamei K, Kusumoto K, Fukumura M, et al. Pulmonary sequestration (Pryce I) with small nodular shadow. J Jpn Soc Bronchol 9: 281, 1987 (in Japanese).

17) Kimura $S$, Uyama $T$, Miura $K$, et al. Systemic arterial supply to the normal lung. J Jpn Assoc Thorac Surg 36: 1012, 1988 (in Japancse).

18) Tutui M, Iwasaki A, Kusano T, et al. A case of pulmonary sequestration (Pryce type I) detected by the aneurysmal dilation of the aberrant artery. Surg Diagn Treat 30: 243, 1988 (in Japanese).

19) Iwasaki $H$, Hashihira $M$, Nakai $H$, ct al. A case of Pryce type I pulmonary sequestration. Jpn J Chest Dis 47: 1053, 1988 (in Japanese).

20) Ozawa K, Sugiura S, Iriyama $T$, et al. Systemic origin of the sole artery to the basal segments of the left lung without pulmonary sequestration. J Jpn Assoc Thorac Surg 37: 529, 1989 (in Japanese). 


\section{Koyama et al}

21) Kato $S$, Nagata $Y$, Shioi $K$, et al. A case of systemic origin of an aberrant artery to the basal segments of the left lung. J Jpn Assoc Thorac Surg 38: 154, 1990 (in Japanese).

22) Takiguchi $Y$, Shishihara $T$, Takahashi $Y$, et al. A case of Pryce type I intralobar pulumonary sequestration diagnosed by non invasive techniques. J Jpn Assoc Thorac Dis 28: 639, 1990 (in Japanese).

23) Savic B, Birtel FJ, Tholen W, Funke HD, Knoche R. Lung sequestration: Report of seven cases and review of 540 published cases. Thorax 34: 96, 1979.

24) Schuman RL, Libby G, Riker J. Pulmonary sequestration with aneurysmal anomalous systemic artery. Vasc Surg 17: 183, 1983.

25) Mclaughlin RF, Couacoud J, Reifenstein GH. Bronchovascular anatomy of intralobar bronchopulmonary sequestration. Am Rev Respir Dis 93: 452, 1966. 